\title{
К ВОПРОСУ ОБ УПРАВЛЕНИИ КАЧЕСТВОМ ПИЩЕВОЙ ПРОДУКЦИИ: МИКРОБИОМЫ ВМЕСТО ПРОДУКТОВ ГМО
}

\author{
Бычков А.А., \\ Студент, «Институт пищевых технологий и дизайна» - филиал НГИЭИ \\ Крайнова О.С., \\ к.э.н., доцент кафедры товароведения и экспертизы товаров \\ «Институт пищевых технологий и дизайна» - филиал НГИЭИ, \\ г. Н.Новгород \\ E-Mail: kraynovaos@mail.ru \\ http://elibrary.ru/author_items.asp?authorid=570168
}

Аннотация. В статье представлен анализ вопроса управления качеством пищевой продукции через призму рассмотрения продуктов ГМО и микробиом. Приводятся конкретные примеры, иллюстрирующие выводы о безопасности/ наличию вреда для здоровья потребителей отдельных видов продукции ГМО. Формулируются преимущества микробиом перед ГМО и обосновывается необходимость совершенствования представленного микробиомного метода в управлении качеством пищевой продукции.

Ключевые слова: управление качеством, качество пищевой продукции, безопасность пищевой продукции, микробиомы, генномодифицированные организмы.

\section{TO THE QUESTION ABOUT THE QUALITY CONTROL OF FOOD PRODUCTS: MICROBIOME INSTEAD OF GMO PRODUCTS}

Bychkov A.A. Student, Institute of food technologies and design branch of «Nizhegorodskiy state engineer-economic university» Kraynova O.S., Candidate of Economic Science, associate Professor of the Department of merchandizing and examination of quality, Institute of food technologies and design branch of «Nizhegorodskiy state engineer-economic university»

E-Mail: kraynovaos@mail.ru http://elibrary.ru/author_items.asp?authorid=570168

Abstract. The article presents an analysis on quality control in food production through consideration of GMO products and the microbiome. Specific examples illustrating the conclusions about no-risk/ presence of harm to the health of consumers of certain products of GMOs. Formulates the advantages of the microbiome before GMOs and the necessity of improving microbiologa presented method in quality control of food products.

Keywords: quality management, food quality, food safety, microbiome, genetically modified organisms. 
ГМО - генномодифицированные организмы - другими словами продукты питания, домашний скот или домашняя птица, в которые путем генной инженерии введен модифицированный генном других животных, насекомых, рыб, морепродуктов или растений для улучшения адаптации этих продуктов к погодным условиям, сопротивляемости вредителям, ускорения созревания и увеличение сроков хранения.

Генетический код изучен на сегодняшний день недостаточно, но это не останавливает ученых оптимистов вторгаться в его природу и пытаться менять его под свой лад. Играя с геномами ДНК, они не задумываются о последствиях. Создавая тем самым генетическую бомбу замедленного действия. Аналогично можно было завести детеныша полосатого тигра у себя дома. Но это ещё половина беды. Самая большая беда состоит в том, что большее население планеты уверена в безопасности и необходимости таких продуктов. За это можно сказать отдельное спасибо некоторым изданиям глянцевых журналов, телевидению и средствам массовой информации. О какой безопасности можно говорить, когда бананы созревают на глазах за несколько часов, а яблоки, ягоды и овощи могут храниться годами на складах, не теряя при этом эстетический вид.

«Я апельсинчик - сочный витаминчик. Я яблочко зеленное, солнцем напоенное. А я персик чудесный, для здоровья полезный.» - именно так выглядят фрукты и овощи на полках магазинов. Вкусные, яркие, свежие - прям как с картинки упаковки или рекламы по телевидению. От ширины ассортимента таких продуктов прилавки на рынках и в магазинах в буквальном смысле трещат по швам. И половины из них нельзя назвать ни полезными, ни свежими, ни натуральными. Химические вещества, которыми обрабатывают продукцию для придания ей более аппетитного вида и увеличения сроков хранения постепенно уходят в прошлое. Нависает угроза куда серьезнее, а 
именно всё более набирает популярность продукция с генномодифицированными организмами. Такие вещества как: патулин, дифенил, бензапирен и пр. могут показаться вполне безобидными по сравнению с тем, что можно ожидать от игр с геномами.

Картофель с геном скорпиона, помидор с генами камбалы. Морозоустойчивый помидор был выведен в результате внедрения в ДНК томата гена морской североамериканской камбалы. Ген скорпиона, внедренный в пшеницу, повышает ее устойчивость к засухе. Вредители тоже имеют способность адаптироваться к разным условиям, и более чем вероятно, что у них появится иммунитет. И эта гонка за урожаем приведет к новым экспериментам с геномами продуктов. Эксперты заверяют нас о безопасности генномодифицированных продуктов. Александр Панчин, кандидат биологических наук, научный сотрудник Института проблем передачи информации РАН помимо всего этого еще и утверждает о необходимости их разработки и усовершенствования для российской экономики, называя противников подобных продуктов носителями «биологической неграмотности». Ведь выращивать продукты собственного производства это и дорого, и долго, что напрочь противоречит политике рыночной экономике. Только вот ярые сторонники такой ГМО продукции, либо забывают, либо намеренно замалчивают факт о полном отсутствии каких-либо витаминов в таких фруктах и овощах, т.к. накопление витаминов и полезных веществ - есть результат процесса фотосинтеза $\left(\mathrm{CO}_{2}+\right.$ $\mathrm{H}_{2} \mathrm{O}+$ солнечный свет) - в ГМО плодах это полностью отсутствует. Трансген (часть ДНК, который переносится при помощи генной-инженерии в геном определённого организма) имеет свойство встраиваться в генный аппарат микроорганизмов кишечника и вызывает мутацию. А мутация приводит к развитию раковых клеток. Трансген, после попадания в организм вместе с пищей, встраивается в генный аппарат микроорганизмов кишечника, в результате чего происходит мутация. Так же он, находясь в организме провоцирует синтез белка, нехарактерный для человека. К тому же все трансгены внедряются в продукцию с помощью специальных бактерий, они в свою оче- 
редь склонны мутировать и быстро размножаться... Онкологи утверждают, что влияние этих компонентов - приводит к мутации клеток, а они в свою очередь образуют опухоли.

Животные, в чей рацион входят ГМО продукты, стареют значительно быстрее, имеют слабый иммунитет и неспособны родить и выносить здоровое потомство. Крысы, питаясь такой продукцией рождают слабых детенышей, уровень смертности которых аномально высок.

В Америке показатель продуктов, в которых используются ГМО достигает $80 \%$, а число людей, больных синдромом дауна в среднем каждый год возрастает на 1\% с 1979 года. Если учесть, что генномодифицированная продукция начала развиваться с начала 1990-х годов, а рождаемость людей с хромосомным заболеванием возросла на 30\% за последние 14 лет, можно проследить зависимость между этими двумя показателями. Начиная с 2000-х годов пища с ГМО подняла процент заболевания на единицу - это серьезный показатель, если учитывать, что прогресс будет только расти.

Рассмотрим, чья продукция содержит ГМО: Kelloggs; PepsiCo; Nestle; Hersheys; Coca-Cola; Cadbury; McDonalds; Similac; Heinz Foods; Mars; Danon; Дарья; Кампамос; Корона; Микояновский; Лианозовский; Царицыно; Волжский ПК

Перечень продуктов, где могут быть ГМО: Соя; Кукуруза; Картофель; Томаты; Кабачки; Свёкла; Пшеница; Морковь; Рис; Масло подсолнечное; Лук; - и продукты, произведённые из них.

Сдерживание роста опасной для здоровья модифицированной пищи должно регулироваться следующими этапами:

1) ужесточением законодательного проекта о контроле над импортными продовольственными товарами;

2) создание организационно-структурного надзора и исполнительного органа за генномодифицированной продукцией;

3) немедленное введение ограничений (заморозки) поставки и реализации на товар, в котором обнаружено содержание ГМО сроком на 1 год; 
4) взыскание штрафов с оптовых и розничных предприятий торговли суммой 1000000 рублей за выявленное нарушение.

Вместо того чтобы играть с малоизученным генетическим кодом, балуясь и внедряя тот или иной генном, существует не менее эффективный способ увеличить урожайность продовольственных товаров и обеспечить устойчивость к гербицидам и вредителям - а именно использовать для продукции их родственников, более близких к ним по семейству. Этот метод основан на перенесении определенных микробиотиков (бактерий) с одного растения на другое. С собранных сорняков, которые произрастают в экстремальных условиях, бактерии и грибы перенесли на стерилизованные семена пшеницы. Комфортное условие для роста обычных семян пшеницы составляет около 37,5 ${ }^{\circ} \mathrm{C}$, при замене микробиома результаты были следующие. Семена пшеницы смогли вырасти в очень экстремальных условиях, недалеко от горячих источников. Покрытые новыми микроорганизмами семена смогли выжить в условиях очень высоких температур. При чем для этого им понадобилось относительно малое количество воды, чем требуется обычно.

Далее в статье рассмотрим симбиотические отношения. Микрофлора кишечника человека оказывает влияние на развитие, психическое здоровье, воспаление, заболевания, пищевую непереносимость и увеличение веса. Фекальные трансплантаты и пребиотики могут быть эффективными при разном состоянии здоровья. Растения, как и люди имеют зависимость от микробов, живущих внутри них, или закрепляющихся на семенах и листьях.

Из всего вышеизложенного возможно сформулировать преимущества микробиом перед ГМО. Так, по сравнению с генномодифицированными продовольственными продуктами микробиомы носят куда более естественный характер. Разумеется, при микробиомном методе вместе с обменом микробами происходит обмен и генами микроорганизмов. Все растения имеют зависимость от своей симбиотической флоры, поэтому эти гены могут также считаться частью этого растения. Наш мир устроен таким образом, что человек, растения и животные постоянно находятся в контакте с новыми микроорга- 
низмами и окружающей средой, и процесс обмена микробиомами среди людей, растений и животных не отличается от естественного процесса, происходящего в окружающей нас среде обитания.

Микробиомный метод довольно интересная и конкурентная альтернатива ГМО, но она еще требует обсуждений и дополнительных испытаний. 